$18 \cdot$ Tempo

\title{
Retórica e Ação Política: A Complexio no Pro Roscio Amerino de Marco Túlio Cícero*
}

\section{Claudia B eltrão da Rosa **}

\section{R esumo}

Anal isamos o uso persuasivo, por Cícero, das expectativas criadas pela educação retórica de sua audiência, em algumas passagens do discurso Pro R oscio Amerino, selecionando uma forma de argumentação específica, a complexio.

Palavras-chave: R etórica ciceroniana - Política - R epública R omana

\section{A bstract}

This paper is an analysis of Cicero's persuasive use of his audience's rhetorically educated expectations in some passages of the discourse Pro Roscio Amerino by selecting an specific argument form, the complexio.

Key-word: Ciceronian rhetoric- Politics- Roman Republic.

\section{R esumé}

Cet article analyse I'usage persuasive, par Cicéron, de las expectatives de son audience, à partir de son education réthòrique, dans quelques passages du $\mathrm{D}$ iscourse

\footnotetext{
* Artigo recebido em julho de 2003 e aprovado para publicação em abril de 2004.

** ProfessoraAdjunta do D epartamento de H istória daU N IRI O.E -mail: cbeltrao@yahoo.com.br e crbeltrao@uol.com.br

Tempo, Rio de Janeiro, no 18, pp. 125-145
} 
Pro R oscio A merino, e centre son analyse sur une forme d'argumentation specifique, la complexio.

M ots-clés: R éthòrique ciceronienne; Politique ; République romaine.

Os discursos de Cícero permanecem extremamente atuais por várias razões. Além de formarem um imenso manancial de informações sobre a R epública romana tardia, foram elaborados a partir da mais eficaz oratória, numa época em que esta era a maior atividade da vida política e núcleo do sistema educacional, e seu autor, o proeminente orador, desempenhou um importante papel no curso dos acontecimentos, em plena cena política. Apesar da longa traj etória de estudos ciceronianos, seus discursos são ainda muito férteis para a pesquisa histórica. I nteressamo-nos, em nossa pesquisa, que visa analisar em detal hes o pensamento político do autor no contexto da retórica e da prática oratória dos tribunais, das assembléias e das sessões do Senado romano, o modo como usava a educação retórica de seu tempo para influenciar sua audiência a dar uma resposta favorável aos seus argumentos. Procedemos pela análise do modo como Cícero, usando uma forma de argumentação particular em discursos específicos, a complexio, movia sua audiência, o que nos permite uma melhor compreensão do contexto do pensamento de sua época, a fim de analisar formas de persuasão nos tribunais, nas assembléias e no Senado, ou seja, nos principais palcos da arena política da República tardia'.

$\mathrm{N}$ o D el nventione, a complexio é tratada como uma forma de argumentação pela qual o orador pode obter conclusões irrefutáveis, através de argumentos ad hominem, basead os na inconsistência das ações ou das declarações

\footnotetext{
${ }^{1} \mathrm{~F}$ undamentam este estudo os trabal hos de M .C. AL EXAN DER, "R epetition of Prosecutions and the Scope of Prosecutions in the Standing Criminal Courts", Classical Antiquity 1 (1982): 141-166; R. G. AUST IN , "T ribunal-Stage-Arena: M odels of the Communications Situation in M. Tullius Cicero'sJ udicial Speeches" R hetorica 7 (1989): 299-311; C. J. CL ASSE N , “Cicero, the $L$ aws and the $L$ aw-C ourts". L atomus 37 (1978); 597-619; J. CR OOK , L aw and L ifeat R ome, Ithaca: Cornell U niversity Press, 1984; D. F. EPST E IN, Personal E nmity in Roman Politics, 218-43 BC. L ondon-N ew York-Sydney: Croom H elm, 1987; E. S. GRUE N, Roman Politics and the Criminal Courts, 149-78 B C. C ambridge, M A: H arvard U niversity Press, 1968; A.H .M. JONES, The Criminal Courts of the Roman Republic and Principate Oxford: Oxford U niversity Press, 1972.
} 
do oponente no contexto forense ${ }^{2}$. Para Cícero, e certamente para os demais oradores, a importância da complexio é o fato de ela ser praticamente invencível. O R hetorica ad $\mathrm{H}$ erennium, contemporâneo do De Inventione, nosso primeiro tratado de retórica helenística, também trata da complexio, denominando-a duplex conclusio, e podemos perceber que a complexio é considerada uma forma de argumentação muito eficaz, pois fornece 0 apoio mais forte a todo 0 argumento (Ad. H er. IV, 52). E m Quintiliano, a complexio não recebe um nome especial, sendo um tipo de divisio. Aqui, contudo, a divisio é uma forma de argumentação, e não uma figura de estilo (I nst. 5.10.69). E m suma, a presença da complexio, seja com que nome for, no Del nventione, no Ad H erennium e em Quintiliano, e recorrente em muitos exemplos, indica seu status como um tópico importante da retórica helenística³.

A compl exio era construída não necessariamente numa forma direta, e dependia, de fato, de um erro presumido do caso, ou da observação de uma inconsistência no comportamento dos envolvidos. Os dois padrões sintáticos que parecem melhor conformar-se com ela são as condições ou as questões al ternadas, diretas ou indiretas. T rata-se, pois, de investigar como Cícero usa esta forma de argumentação em sua tarefa de persuadir nos tribunais. Temos como premissa que o estilo, compreendido no sentido da escolha das palavras e das formas sintáticas, com suas repetições e variações internas, tinha um papel vital nos processos judiciais. $\mathrm{H}$ á, então, o fenômeno de a forma não

${ }^{2} \mathrm{~N}$ o I nv. I . 83-84, Cícero ensina como reconhecer uma compl exio fal sa e refutá-la. Sob o nome de comprehensio, a teoria retórica helenística já apresentara duas táticas para desconstruí-la, sendo que a primeira, a conversio, tem sua base na R het. 2.23 de Aristóteles. Como um ótimo exemplo, Cícero faz com que César coloque Crasso numa complexio, no D e Or. II. 367: H. M . HUBBEL (E d. e Trad.) Cicero II. De inventione, De Optimo Genere Oratorum, Topica, 2a ed., Cambridge, M A: H arvard U niversity Press, 1976, L oeb Classical L ibrary.

${ }^{3} \mathrm{~A}$ mais antiga referência teórica à complexio su rge, para nós, primeiro em A ristóteles. E m seu catálogo das fontes de premissas para entimemas, ele dá um exemplo de um argumento deste tipo: P or exemplo, uma sacerdotisa queria proibir seu filho dese engajar num debate público. 'P ois', ela disse, 'se disseres o justo, o povo te odiará, mas sedisseres o injusto, serão os deuses a teodiar'. (...) [ então, ela continua] 'Tu então te engajas no debate público' se dizes o justo, os deuses te amarão, se dizes o injusto, o povo te amará (...): R het. 2.23.1399 1 19-29. Aristóteles, porém, não nomeia este tipo de topos. A natureza deste exemplo é decisiva para nós: surge num contexto nãooratório e é interessante vê-lo citado como uma ilustração de topoi, inserido, portanto, numa retórica formal; e depende das circunstâncias externas, visand o uma ação futura, mas há outro exemplo, também na R etórica, adscrito a X enófanes: $R$ het. 2.23.1400b 5-8., que não se remete a acontecimentos futuros, mas à fal ta de coerência entre uma ação presente e as ações passadas. 
somente reforçar o conteúdo, mas real mente igualar-se ao conteúdo, levando à persuasão. N este sentido, a forma é o argumento. A complexio, então, é uma forma de se apresentarem argumentos irrefutáveis, geralmente contra o acusador ou uma testemunha, demonstrando a falta de consistência de suas declarações ${ }^{4}$. Vemos que se trata de dar ao adversário a escol ha entre duas alternativas, sendo que uma necessariamente terá de ser escolhida e, como resultado, seja qual for a escol hida, o adversário será prejudicado. H á sempre duas possibilidades a escolher; uma deveráser válida e o oponente tem o poder da escolha, mas qual quer escolha o prejudicará, e ela tem nitidamente a forma de questões alternativas, diretas ou indiretas, no esquema se $P$, então $X$, mas seQ, então Y. N ossa questão geral é: como Cícero manipulava sua audiência com o uso da complexio? Acreditamos que a resposta a esta questão pode lançar luz sobre os procedimentos e o funcionamento dos tribunais, das assembléias romanas e do Senado. Procedemos, então, pela análise de cada discurso, em termos de sua unicidade, incluindo seus aspectos legais específicos, suas ramificações políticas e a "opinião pública" da época, comparando a prática oratória de Cícero com sua teoria retórica, ao observarmos exemplos que refletem os preceitos dos manuais ou as técnicas tradicionais da prática oratória. N ossa abordagem é, então, justaposta, visando uma melhor compreensão do papel das formas de argumentação nos discursos ciceronianos.

Vejamos, então, o primeiro caso criminal de Cícero, o P ro R oscio Amerino, que tomamos como um modelo para o tratamento das estratégias usadas pelo orador, no início de sua carreira, na análise detalhada dos demais discursos que formam o corpus textual desta pesquisa (Divinatio in Caecilium, Pro R oscio Comoedo, Pro Sulla, Pro Caelio, Pro Plancio e all F ilípica), pois permite estabelecer o contexto em que Cícero usava suas formas de argumentação e seu papel na persuasão.

A defesa de Sex. R óscio de Améria, por Cícero, da acusação de parricídio, em 80 , é o primeiro discurso do orador num contexto criminal. Ao lado

${ }^{4} \mathrm{O}$ estudo do estilo quanto ao fim persuasivo já rendeu ótimos frutos, como: J. AXER, The Style and Composition of Cicero's Speexh Pro Q. R oscio Comoedo, Warsaw: Wydawnictwa Uniwersytetu Warsawskiego, 1980; H. C. G OT OF F, Cicero's E legant Style: an Analysis of the P ro Archia, U rbana: U niversity of I llinois Press, 1979; os ótimos comentários de L acey, na tradução da II F ilípica, de Warminster: Aris \& Phillips, 1996, e de F. P. D onnelly nas edições do Pro Milone, N ew York, Bruce, 1935, e do P ro L ege Manilia, N ew York, F ordham U niversity Press, 1935. BUT L ER, H.E. (ed. e trad.) Quintilian. 4 vols. Cambridge, M A: H arvard University Press, 1960: L oeb Classical Library. 
de seu discurso civil Pro Quinctio, do ano anterior, é o primeiro discurso ciceroniano de que dispomos. $N$ estes trabal hos, não são freqüentes as formas da complexio, mas o discurso em favor de Róscio de Améria nos pode revelar, de modo útil, o papel presentacional dos argumentos na forma da complexio no início da carreira oratória de Cícero. A o contrário dos outros seis discursos que nos propomos a estudar, o Pro Roscio Amerino é útil principalmente por sua posição cronológica em meio aos discursos ciceronianos, e não por conter um uso freqüente ou integral das formas da complexio para permitir demandas especiais ao desafio retórico. D esta forma, um estudo altamente detalhado da argumentação neste caso não seria útil, sendo para nós suficiente examinar o papel de cada uso em seu contexto argumentativo imediato.

Segundo Cícero, estes são os fatos: um certo R óscio, cidadão rico de Améria e partidário entusiástico de Sila (§§ 15-16), fora assassinado em Roma (§ 18). N ão sabemos exatamente a data, mas 0 assassinato provavelmente ocorreu antes de 1 - de junho de 81 (§ 128). 0 companheiro de viagem e conterrâneo da vítima, T. R óscio M agno, foi responsabilizado pelo assassinato e imediatamente enviou um mensageiro a Améria, para anunciar a morte de R óscio a seu companheiro T. R óscio C apito (§§ 19,96-98). Q uatro dias depois, M agno e Capito foram ao campo de Sila, em Volaterrae, para informar a Crisógono, o poderoso liberto de Sila, da morte de R óscio. Sob instigação de $M$ agno e C apito, e sem o conhecimento de Sila, C risógono inseriu o nome da vítima na lista dos proscritos, e suas propriedades foram leiloadas (\$§ 20-22, 105-107). Crisógono, então, comprou estes bens, avaliados em cerca de 6 milhões de sestércios, pelo montante de apenas dois mil sestércios $(\$ \S 6,21)$. R ecompensou a $C$ apito com três propriedades da vítima, fazendo de $M$ agno seu agente para administrar os bens $(\$ 21,108)$. M agno parte para Améria e expulsa o filho da vítima, o cliente de Cícero, de sua casa. 0 povo de Améria, que conhecia o morto como um partidário incondicional dos nobiles, ficou chocado com este aparente erro de Sila. Por um decreto da cúria municipal, foi enviada uma embaixada de dez cidadãos ilustres a Sila, em Volaterrae, para explicar-Ihe que o velho Róscio não deveria estar entre os proscritos (§§ 2326). U m dos membros da embaixada era C apito, e C risógono persuadiu, com o auxílio do primeiro, esta del egação de que corrigiria o erro e cuidaria da restauração dos bens do jovem Róscio. Satisfeitos, os delegados voltaram para casa sem verem Sila (\$§ 26,109-110). C risógono, M agno e Capito, após outras conversas, decidiram finalmente que o único meio de usufruírem das proprie- 
dades em paz era matando o jovem herdeiro (§ 26). D epois de uma tentativa fracassada de assassinato, vemos o jovem R óscio em R oma, onde foi auxiliado por um amicus da gens Caecilia (§ 27). Crisógono, M agno e Capito, com dificuldades agora para matar o jovem, usam do expediente do assassinato judicial. A gindo por meio de um acusador pago, um certo C. E rúcio ( $\$ \S 55,58)$, acusaram o jovem Róscio de parricídio. Se fosse considerado culpado, o jovem seria condenado à morte, e Crisógono não teria mais empecilhos. A acusação devia ser confiável, pois era o primeiro jul gamento criminal depois de um bom tempo, e desejava-se, em geral, o retorno à normalidade, após a guerra civil e as proscrições. M aisimportante ainda, com Crisógono envolvido no caso, parecia a todos que Sila tinha interesse na condenação (§§ 28-29). I sto nos explica porque patroni proeminentes não se arriscaram a aceitar a defesa de R óscio (§§ 1-4). E ste papel perigoso de defensor coube ao jovem Cícero.

A versão da acusação sobre os eventos era diferente ${ }^{5}$. E rúcio argumentou que o velho Róscio e seu filho não se davam bem (\$ 40 ). 0 jovem Róscio tinha um irmão, já falecido, que o pai mantivera consigo em Roma, enquanto o cliente de Cícero era relegado a Améria (\$ 42 ). 0 acusado, segundo E rúcio, acreditava que seu pai iria deserdá-lo (§52), o que era um motivo forte para um assassinato. $H$ ouve também a oportunidade. $M$ esmo que $E$ rúcio, ao que parece, não tenha sustentado que o acusado estivesse em Roma à época do assassinato, o crime ocorreu num período violento, no qual um assassinato não era al go difícil de se encomendar (\$ 80). F inalmente, apresentou outras indicações para uma suposta natureza criminosa do acusado (§ 82).

E rúcio, enquanto deixava claro que C risógono favorecia a acusação (§ 132), não menciona que o velho Róscio fora posto entre os proscritos, ou que seus bens foram leiloados ( $5-6,28)$. Além disto, se 0 acusador mencionasse a proscrição do velho Róscio, isto implicaria que a vítima fora legalmente morta, o que invalidaria a acusação de assassinato. M encionar que os bens foram vendidos, sem admitir que a vítima estava entre os proscritos, implicaria que a venda forailegal, e os bens teriam de ser devolvidos ao jovem Róscio. D esta forma, a acusação devia proceder como se a proscrição e a venda dos bens jamais tivessem ocorrido.

E stes detal hes na acusação eram o mai or problema do discurso. Por que Crisógono e seus asseclas construíram uma situação que poderia prejudicá-

${ }^{5}$ KIN SE Y, T. E . “Cicero's Speech for R oscius”, Symbolae0 0sloenses 50 (1975): 91-108, pp. 96-97. 
los? D eixaram duas opções a Cícero, no tocante à proscrição do velho R óscio. 0 orador poderia argumentar que a vítima fora legalmente incluída entre os proscritos e demolir os fundamentos legais da acusação de parricídio, ou poderia aceitar a posição da acusação e não divulgar que a vítima estava entre os proscritos e, então, um assassinato fora cometido. Aceitar a versão de que o velho R óscio fora assassinado, e não legalmente morto, significava que suas propriedades não podiam ser legitimamente leiloadas e, então, C risógono e os outros teriam efetivamente roubado a herança do acusado. E ntão, a acusação levou Cícero a escolher entre posições que viciavam a acusação, ou demonstravam que os que estavam por trás dela agiam ilegalmente ${ }^{6}$.

U ma explicação simples para esta aparente estupidez é que C risógono e os outros realmente acreditavam que a intimidação prevaleceria; que a defesa não ousaria dizer que C risógono estava de posse dos bens do morto e, mesmo, que não ousaria criticá-lo, pois um ataque a ele equivaleria a um desafio ao próprio Sila. Além disto, era al go que atingiria os que compraram propriedades dos proscritos em leilão, como vários membros do júri.

0 único motivo plausível para a defesa mencionar o destino dos bens da vítima era 0 apoio à tese de que não houve assassinato, pois a vítima era um proscrito. $M$ as a acusação parecia segura de que a defesa não sustentaria a tese da proscrição. Todos sabiam que tal defesa legalista do parricídio, mesmo que juridicamente correta, seria repugnante ao júri. U ma tese conciliatória, de que o morto estava entre os proscritos, mas que o jovem R óscio não o matara dificilmente seria eficaz numa defesa de parricídio.

A escolha de Cícero foi tratar a morte do velho Róscio como assassinato, insistindo na ilegalidade da aquisição de seus bens por C risógono. E sta escol ha ligava-se a considerações políticas quanto à facção de Cícero. 0 jovem R óscio era apoiado por alguns dos mais eminentes membros do regime de Sila ${ }^{7}$. Se acreditassem que Sila estivesse por trás de C risógono neste caso, dificilmente apoiariam a defesa de Cícero. 0 caso punha à prova a nobilitas, temerosa no tempo das proscrições, em seu comportamento no retorno à "normalidade". Sila estabelecera a primazia do Senado tanto no governo como nos tribunais, incluindo as novas quaestiones perpetuae. E nfim, era um bom momento para testar o sistema. 0 papel de Cícero parece ter sido o de um

${ }^{6}$ T. E. KIN SE Y, “A problem in Pro Roscio Amerino", E ranos 79 (1981): 149-50.

${ }^{7}$ GRUE N, op. cit., pp. 265-71. 
porta-voz de alguns dos mais destacados colaboradores de Sila, num caso contra C risógono, apesar de Cícero não ser partidário do ditador.

E ste papel, mesmo que não fosse exatamente o papel heróico contra Sila, que Cícero decanta no D e Officiis, II, 51, era perigoso. A ausência, no tribunal, de patroni eminentes e, mesmo, dos membros das famílias importantes que apoiavam Róscio, mostrava que havia muita incerteza sobre as possíveis reações do ditador quanto a um ataque a seu liberto preferido.

U m dado óbvio para compreendermos a escolha da estratégia por Cícero é que ele deveria real mente defender seu cliente de uma acusação de assassinato. Sua principal tarefa era destruir os argumentos de E rúcio, todos derivados da probabilidade de que $M$ agno e Capito fossem os responsáveis pelo assassinato, e não 0 acusado ${ }^{8}$. As al egações de Cícero contra M agno e $C$ apito eram fracas e inconsistentes, mas ele precisava somente mostrar que os argumentos de E rúcio também eram fracos, para ter sucesso.

Torna-se claro o perigo da posição de Cícero. 0 orador evitou apresentar a hipótese mais forte, i.é., a de que o próprio C risógono planejou 0 assassinato, assim como os eventos subseqüentes. Claramente, Cícero considerou ser perigosamente simples acusar o poderoso liberto, do mesmo modo que também o seria se declarasse que a vítima estava entre os proscritos. Atribuir tal ação a um homem de Sila seria o mesmo que atacar a consistência e a validade dos princípios sob os quais todos os proscritos foram mortos. E $m$ vez disto, $M$ agno e C apito entravam em cena. M esmo que dificilmente fossem os assassinos propriamente ditos, juntos podiam ter formado um complô de assassinato verossímil, uma alternativa para a defesa, que não atingiria diretamente Sila.

E m suma, o objetivo de Cícero era duplo. D everia atingir as ações de C risógono, condenando-as como anti-silanianas, e refutar as acusações contra seu cliente. M esmo que tivesse apoio na facção de Sila, Cícero corria o risco de ofender o ditador ou o júri. 0 desafio que enfrentou era o de levar a cabo sua defesa de modo que atingisse os dois objetivos sem comprometer Sila, nem aprovar as ações de seu liberto, tampouco causando desconforto no júri, cujos membros, em grande parte, se aproveitaram das proscrições, aumentando ou criando sua riqueza.

${ }^{8}$ Antikategoria; cf. Quintiliano, Inst. 7.2.9, 18-25 e 3.10.4. 
Ainda que este desafio não tenha sido formulado explicitamente, a resposta de Cícero aos seus vários aspectos vem sendo objeto de muitos bons estudos. Para nossos propósitos, é suficiente rever o corpo geral deste discurso e o uso da complexio nos seus argumentos. Percebemos claramente, a partir do que já expomos sobre o caso, que a complexio deviaser dirigida não apenas contra E rúcio, o acusador, mas também contra outros adversarii do orador: Magno, C apito e Crisógono.

0 exordium (§§ 1-14) reflete a apreensão de Cícero quanto à sua inexperiência e à falta de patroni mais bem qual ificados para o caso. L ogo de início, declara que C risógono é a razão desta apreensão e que a ganância deste é o motivo da acusação ${ }^{9}$. E o orador assegura que deseja um júri severo e rigoroso, a fim de conter os verdadeiros assassinos, que atacam indevidamente 0 seu cliente.

A narratio (§§ 15-34) apresenta a versão dos eventos que já comentamos em linhas gerais. Sua conclusão emocional (§§ 29b-34) inclui a primeira forma de complexio do discurso:

Pater occisus nefarie, domus obsessa ab inimicis, bona adempta, possessa, direpta, fili uita infesta, saepeferro atque insidiis appetita. Quid ab his tot maleficiis scel eris abessevidetur? Tamen haec aliis nefariis cumjlant atqueadaugent, crimen incredi bile confingunt, testis in hunc et accusatores huiusce pecunia comparant: hanc condicionam mider o ferunt ut optet utrum malit cer vi ces T. R oscio [sc. M agno] darena insutus in culleum per summum dedecus uitam amittere. (§30).

Seu pai assassinado de maneira atroz, sua casa tomada por inimigos, suas propriedades confiscadas, atacadas e pilhadas, a vida de seu filho ameaçada, freqüentemente assaltadas pela traição e pela espada - que tipo de crime pode ser cometido entre tantos outros? E les ainda os coroam e agravam por outros atos ímpios. Inventam uma acusação inacreditável, subornando, com o próprio dinheiro de meu cliente, testemunhas e acusadores para depor contra ele, e reduzem o infeliz à al ternativa de escolher se prefere oferecer o seu pescoço a T ito Róscio [sc. M agno] ou ser costurado num saco e perder sua vida pela morte mais infamante.

$\mathrm{N}$ esta passagem, plena de argumento patético, vemos o próprio defensor confrontado com uma terrível aporia, em que todas as alternativas levam à morte de seu cliente. Tecnicamente, esta não é uma complexio verdadeira,

${ }^{9}$ E ste ataque explícito a C risógono, logo no início da defesa, é analisado por KE N N E D Y, op. cit., pp. 152-53. 
pois não é dirigida ao oponente, mas um argumento em forma de complexio, visando suscitar a piedade em relação ao jovem Róscio. Vemos Cícero usando esta forma como um argumento emocional, de um modo que ele não empregou no De Inventione Além disto, não temos exemplos deste uso na oratória romanaanterior. E ste tipo de complexio, na função, é similar àcomplexio de C. G raco, mas, fundamentalmente, difere no sentido em que as duas alternativas são real mente exaustivas, e as conseqüências de ambas são materialmente perigosas. Assim, ao contrário do exemplo de $\mathrm{C}$. G raco, pode ser considerada, mais apropriadamente, uma forma de complexio.

A partitio (§§ 35-36) lista os três pontos-chave da argumentatio: a refutação da acusação de E rúcio (parricídio), os abusos de $M$ agno e C apito e a influência de C risógono. A primeira seção da argumentatio (\$§ 37-82) refuta as acusações de E rúcio, principal mente com base nas categorias de argumentos ex persona, ex causa e ex negotio, ou seja, caráter, motivo e circunstâncias em torno do crime ${ }^{10}$. 0 tema dominante de Cícero é o fato de o parricídio ser 0 maior dos crimese, então, requerer um motivo grave, que E rúcio não demonstrou. Amplificando este argumento básico, numa longa narrativa que inclui a famosa passagem sobre o parricídio nas seções $\S 7 \S 1-73^{a}$, é enfatizada a incapacidade de E rúcio em demonstrar um motivo forte, contentando-se em explorar os meios pelos quais o jovem R óscio supostamente cometera o crime:

Quo modo occidit? ipsepercussit na aliis occidendum dedit? Si ipsum arguis, R omae non fuit; si per alios fecisse dicis, quaero quos? Servosne na liber os? Si liber os, quos homines? Indidemne Ameria na hosce ex urbesicarios? Si Ameria, Qui sunt ei? Cur non nominantur? Si R oma, unde eos noverat Roscius qui R oman multis annis non venit nequeumquam plus triduo fuit? U bi eos convenit? Qui conlocutus est? quo modo persuasit? N onnehis vestigi is ad caput malefici perveniri solet? (§74)

Como o matou? E le mesmo desferiu o golpe ou encarregou a outros tal tare$\mathrm{fa}$ ? Se você sustenta que ele mesmo o fez, respondo que ele não estava em R oma; se você diz que ele o fez pelas mãos de outros, eu pergunto, quem são? E scravos ou livres? Se livres, quem são? D a própria Améria ou seriam alguns desses sicários de R oma? Se são de Améria, quem são? Por que não são nomeados? Se são de R oma, como foi que R óscio, que não vem a R oma há vários anos e nunca permaneceu aqui por mais de três dias, os contactou? Q uando ele os encontrou: como se reuniu com eles: como os convenceu: ele os subornou; a quem? Por quem? de onde veio o dinheiro, e qual a quantia? $\mathrm{N}$ ão

10 Inv. I. 34-43; II . 16-51. 
é seguindo esses vestígios que normal mente se investiga o desenrolar de um crime?

Cícero, então, começa a apresentar seus argumentos ex negotio, com uma série de três grupos de alternativas. R óscio cometeu o assassinato com suas mãos ou o encomend ou? A primeira al ternativa é logo negada como impossível, e a segunda é dividida em duas outras. E le encomendou o crime a escravos ou a homens livres: a possibilidade de que homens livres fossem seus agentes é, então, subdividida na consideração de se eram homens livres de Améria ou de R oma, e negada na lista posterior de questões.

0 tratamento por Cícero da alternativa final, de que os agentes de R óscio eram escravos, elucida as relações entre a demonstração de raciocínios invencíveis e de premissas fundadas em argumentos éticos. $\mathrm{N}$ esta seção do argumento, a idéia de que R óscio encomendou o assassinato é insustentável, mas não é total mente impossível. $\mathrm{N}$ ão bastava, dada a natureza da acusação, que Cícero demonstrasse que esta não podia ser provada. T inha de persuadir o júri de que a acusação sequer podia ser levantada de modo plausível. 0 único apoio para tal demonstração era que a audiência aceitasse o retrato que Cícero apresentava de Róscio, com um caráter simples e rústico. E ntão, o orador trata da alternativa final, de que os agentes de R óscio eram escravos ( $\S$ 77-78), com uma praeteritio que sublinha que planejar um assassinato não está de acordo com os modos rústicos que a acusação atribuía ao caráter de Róscio ( $\S$ 77, E t simul - 78) e uma amplificação da tese de que $\mathrm{R}$ óscio, dada a imagem rústica que a acusação Ihe atribuía, não poderia conhecer ninguém que pudesse cometer o crime em R oma (§79).

Cícero trata esta possibilidade após tratar a hipótese de homens livres como agentes do crime, revertendo a ordem original das alternativas apresentadas no $\S 74$, o que Ihe permite encerrar esta argumentação forte. D eslizando do tópico de escravos como assassinos para o de escravos como testemunhas, ele destaca que os escravos da vítima eram aparentemente as únicas testemunhas oculares do crime, e que Crisógono se recusou a permitir seu depoimento. $\mathrm{E}$, deixando momentaneamente $\mathrm{M}$ agno e $\mathrm{C}$ apito de lado, recapitula sua série de alternativas:

$\mathrm{N}$ unc, E ruci, ad te venio. Conveniat mihi tecum necesse est, si ad hunc maleficium istud pertinetm aut ipsum sua manu fecisse, id quod negas, aut per aliquos liber os aut ser vos. L iberosne? Quos nequeut convenire potuer it nequequa rationeinducer eneque ub neque per quos neque qua spe aut quo pretio potes ostendere. E go contra ostendo 
non modo nihil eorum fecisse $S$ ex. R oscium sed nepotuissequidem facere, quod neque R omae multis annis fueri neque de praediis umquam temere descesserit. Restare tibi videbatur servorum nomen, quo quasi in portum reiectus a ceteris suspicionibus confuger eposses; ubi scopulum offendis eius modi ut non modo ab hoc crimen resilire videas omnem suspicionem in vosmet ipsos recidere intel legas (\$79)

Agora, E rúcio, tratarei de você. Temos necessariamente de concordar que, se meu cliente tem ligação com este crime, ou ele o cometeu com suas próprias mãos, o que você não é capaz de provar, ou o fez por intermédio de outros, homens livres ou escravos. H omens livres? Você não foi capaz de demonstrar como ele poderia encontrá-los, por quais meios os persuadiu, por intermédio de quem, que expectativas ele tinha, que suborno ofereceu. E u, ao contrário, provo que Sexto R óscio não somente não fez, mas que não poderia ter feito nenhuma dessas coisas, posto que, por muitos anos não esteve em R oma, nem deixou sua propriedade sem uma boa razão. Parece que a única coisa que te resta é nomear os escravos; isto parece um tipo de porto em que você pode se refugiar quando se dirige a suas outras al egações falsas, em vez do que você se apega como a um tipo de rocha, sem conseguir ver que simplesmente as acusações ricocheteiam dele [Sex. R óscio]e que cada suspeita recai sobre vocês mesmos.

A idéia de que R óscio cometera o crime com suas próprias mãos é aqui refutada brevemente. Cícero trata, apenas, da alternativa entre homens livres ou escravos como agentes. Os argumentos éticos apresentados inicialmente nesta cadeia de raciocínio e o simples fato da repetição e a insistência na recusa de Crisógono de entregar os escravos fazem a demonstração parecer irrefutável. As declarações da acusação foram transformadas, passando de insustentáveis a impossíveis. D e certo, isto é apenas uma ilusão criada no discurso, pois alguém que, em R oma, se hospedasse na casa de Cecília, muIher que tinha relações familiares com ambos os cônsules el eitos, não poderia ser completamente ignorante dos acontecimentos da urbs.

0 tratamento dos argumentos ex negotio tem sua estrutura baseada na apresentação de al ternativas que poderiam fazer do relato do oponente al go aceitável. Cada alternativa é, então, apresentada como insustentável. M esmo que não seja a forma usual do procedimento, como Cícero a apresenta no D e Inventione, I, 44-45, esta estrutura argumentativa está de acordo com a definição de Q uintiliano de compl exio e com seu exemplo no P ro Vareno. Além disto, notamos que o argumento não é irrefutável. Cícero enfatiza argumentos de caráter, a fal ta de provas de seu oponente e a simples repetição, acrescentando um componente de persuasão extra-racional à lógica de sua demons- 
tração. E ntão, transforma o "insustentável” no "impossível” . 0 rigor aparente da estrutura argumentativa ajuda a dissimular a natureza extra-racional deste deslocamento e a criar um clima de irrefutabilidade numa conclusão que é, no mínimo, discutível. A complexio desempenha o papel principal nesta criação de uma impressão de rigor.

A segunda seção daargumentatio liga-se à audacia de $\mathrm{M}$ agno e de $C$ apito (§§ 83-123). U sando novamente os tópicos de motivo, caráter e argumentos ex negotio, Cícero mostra que os R oscii são mais provavel mente suspeitos do que o seu cliente. É interessante que esta seção seja aberta com a insistência de Cícero de que não deseja desempenhar o papel de acusador (\$ 83). 0 fato de que o orador não faz uma acusação decisiva contra M agno e C apito é um grande indício de que simplesmente não podia fazê-lo. M esmo que as circunstâncias, principalmente a venda da propriedade da vítima, fossem agravantes, não havia qualquer laço substancial entre $M$ agno, Capito e o assassinato propriamente dito. Por sorte, Cícero precisava apenas comparar ambos com seu cliente e mostrar que eram suspeitos mais prováveis do que o jovem R óscio. I nfelizmente, porém, esta comparação de probabilidades era também fraca. 0 orador começa com a questão básica de motivação: Quem ganharia mais com isto? (§ 86). M as, na versão ciceroniana dos eventos, $M$ agno não teria usufruído de nada após o assassinato, enquanto R óscio podia assegurar-se a herança com a morte de seu pai. E ntão, a única saída de Cícero era dar ênfase às pressuposições sobre o caráter e ocultar a inconsistência de sua versão, ao contrastar o avarento, hostil e empobrecido M agno com o honesto, rústico e afável Sex. Róscio (§§ 86-88).

Cícero mantém sua estratégia, mesmo faltando-Ihe coerência, no ataque seguinte aE rúcio (\$§ 89-91), um ataque notável pelo encadeamento das idéias: $M$ agno é maldoso e pronto a acusar. E rúcio podia acusá-lo, e ele era um bom acusador, principalmente porque os melhores acusadores foram mortos na guerra civil. $\mathrm{N}$ estes tempos turbulentos, muitos foram mortos impunemente, enquanto os líderes (i.é., Sila) de nada sabiam. Finalmente, Cícero diz que estes assassinos foram levad os à justiça, mas reafirma que não está agindo como um acusador.

E ste exercício de pensamento não oferece, porém, nenhuma garantia de que $M$ agno tivesse algum motivo especial para o assassinato. Cícero conclui (§ 92) que houve, então, muitos motivos que levaram M agno a matar! 0 efeito dos temas e o simples volume das palavras completavam o argumento. 
A pós considerar, ostensivamente, os supostos motivos, o orador chega aos meios. Assim como no primeiro argumento ex negotio, a noção de que Róscio não era uma criatura de R oma e, implicitamente, não tinha ninguém na cidade para cometê-lo éfundamental. Quando o crime foi cometido, M agno estava em R oma, e R óscio, não. Infere-se que M agno é, mais provavelmente, 0 assassino. A objeção lógica de que R óscio era perfeitamente capaz de cometer o crime à distância é tratada por Cícero do seguinte modo:

E rat tum multitudo sicariorum, id quod commemorauit $E$ rucius, et homines impune occidebantur. Quid? ea multitudo auqe erat? O pinor, aut eorum qui in bonis erant occupati, aut eorum qui ab eis conducebantur, ut aliquem occider ent. Si eos putas qui alienum appetebant, tu es in eo numero qui mostra pecunia dives es; sin eos quos qui leuiore nomine appellant percurssores vocant, quaere in cuius fide sint et dientela; mihi crede, aliquem de societate reperies (§ 93).

N esta época havia uma multidão de assassinos, como $E$ rúcio nos disse, e homens eram assassinad os impunemente. Por quem esta multidão era composta? I magino que tanto por aqueles que estavam ocupados comprando bens como por aqueles instigados pelos primeiros a matar al guém. Se você pensa que os criminosos eram aquel es que se apropriaram dos bens de outrem, você está entre eles, você que se enriqueceu com a nossa riqueza; mas se você pensa que são chamados pelo nome mais leve de bandidos, procure saber sob qual proteção e em qual clientela estão e, creia-me, você encontrará al gum de seus associados.

Todo o argumento de Cícero é baseado na descrição do caráter moral de R óscio e de M agno. 0 orador não precisa repetir a (improvável) incapacidade de R óscio de cometer o crime. E m vez disto, confronta M agno com uma complexio, da qual o primeiro lance é fundado na questão de quem mais ganhou com o ocorrido, e o segundo, na declaração admirada de que, como criminosos sanguinários, estavam à solta na urbs, e M agno morava em Roma, logo, este se ligava aos criminosos. Aqui, o argumento é baseado simplesmente na caracterização prévia dos envolvidos e numa mera ressonância temática com a associação feita nos $\S \S 89-91$. N este contexto, a complexio tem uma função dupla. Primeiro, garante uma impressão de rigor a um argumento virtual mente incoerente, baseado em assunções extraídas de uma descrição de caráter. Segundo, e igualmente importante, é também um veículo para reforçar esta descrição negativa do caráter.

A quinta instância da forma de complexio no discurso não é uma complexio verdadeira, mas difere da dos manuais de retórica de um modo especialmen- 
R etórica eAção P olítica: A Complexio no P ro R oscio Amerino de M arco T úlio Cícero

te útil para a ocasião. N o final do tratamento de M agno e C apito (§§ 119-123), Cícero retoma o tema dos escravos da vítima, que Crisógono e seu agente, $\mathrm{M}$ agno, se recusavam a permitir interrogar. Cícero pergunta aos "melhores homens do E stado" se eles foram vendidos. Pergunta em nome de um filho prostrado pela dor e prestes a descobrir a verdade sobre 0 assassinato de seu pai: Res porro abs te eius modo postulabatur ut nihil interesset, utrum eam ream recusares na demaleficio confiter ere. Quam cum ita sint, quaero abs tequam ob causam recusaris ( $\$ 120$ ). [A lém disto, a pergunta feita a você é de tal modo que não faz diferença você recusar ou confessar o crime. Sendo assim, eu Ihe pergunto por que você recusa.]

O fato de que os escravos não foram chamados para o interrogatório é, ao lado do destino dos bens da vítima, a principal evidência que Cícero oferece contra seus oponentes. A propriadamente, 0 orador apresenta a principal delas nas duas primeiras das três principais divisões de seu argumento (§§ 77-79, 119-123). N a última passagem, reforça esta ênfase com uma forma de complexio que apresenta, no passado, duas escol has aos seus oponentes. Seja qual for a escolhida, revelará a culpa de M agno no assassinato. E sta forma, uma complexio que confronta o oponente, difere do procedimento descrito nos manuais de retórica justamente porque não oferece escolha concreta no presente. Além disto, é fundamentalmente diferente da complexio dirigida a um oponente, que percebemos nos oradores áticos ${ }^{11}$. N estes, a complexio narrativa simplesmente enfatiza a cul pabilidade presumida do alvo. Tal forma de complexio narrativa parece tão enfática quanto uma normal, mas impede mesmo a possibilidade de o oponente retrucar.

Sabemos que tanto o defensor como o oponente podem ser 0 alvo de uma complexio, com resultados muito diferentes. $\mathrm{N}$ o início da terceira divisão principal da argumentação, ligada a C risógono (§§ 124-142), percebemos que foi útil para Cícero propor uma complexio para si próprio:

Venio nunc ad illud nomen aureum Chr ysogoni sub quo nominetota societas latuit: de quo, iudices, nequequo modo dicam nequequo modo ta ceam reperirepossum. Si enim taceo, vel maximam partem relinquo; si autem dico, vereor ne non ille solus, id quod ad me nihil attinet, sed alii quoque plures laesos se putent. Tametsi ita res habet ut mi hi in communem causam sectorum dicendum ni hil magno operevideatur; haecenim causa nova profecto et singularis est (§ 124).

${ }^{11}$ Cf. I sócrates, 17. 27-28, in N OR L IN , G (ed. e trad.) I socrates. 3 vols. L ondon: H einemann, 1969: Loeb Classical Library. 
Chego agora ao áureo nome de Crisógono, sob o qual toda a associação é encoberta. E stou perdido, jurados, sem saber como falar deste nome, ou como permanecer em silêncio sobre ele. Se permaneço em silêncio, omito uma parte importante do meu argumento; se o menciono, temo que não apenas C risógono - o que é indiferente para mim - mas muitos outros poderão se sentir insultados. Contudo, o caso é de tal natureza que eu preciso dizer muito contra estes genericamente; pois este caso é seguramente de um caráter novo e singular.

0 orador tinha de lidar com o tópico delicado da aquisição da propriedade do velho Róscio por Crisógono, problemático porque muitos, talvez todos, no júri senatorial, se aproveitaram das proscrições. Q uestionar a legalidade de tais aquisições poderia tornar o júri extremamente hostil a Cícero, não importando aqui sua predisposição contra Crisógono ou seu desejo de honrar o juramento do tribunal. Antes que os jurados se indignassem e alegassem questões de dever ou de auto-interesse, Cícero dilui esta tensão, explicitando-a e proclamando que este tópico era um problema para ele. Ao mostrar que era sensível aos interesses dos jurados, de modo que não os ofendesse por terem estes interesses, o orador torna claro que investirá apenas contra seus oponentes e contra ninguém mais. E sta declaração Ihe garante uma licença para tratar o tópico embaraçoso da aquisição da propriedade de R óscio, assegurando ao júri que este é o um caso que não afetaráa legal idade de suas próprias aquisições. E ntão, o endereçamento de uma complexio a si mesmo foi muito útil para o seu caso.

U ma forma final de complexio, neste discurso, é muito interessante, primeiro por sua posição no argumento. $\mathrm{N}$ o ataque a Crisógono, Cícero começa por argumentar que erailegal o leilão das propriedades do vel ho R óscio, porque ele não fora colocado na categoria dos demais proscritos. Se o assassinato não foi legal, então o leilão das propriedades não podia sê-lo (§§ 125126). A pós novamente declarar que não estava criticando Sila, mas apenas C risógono, enfatiza que a compra dos bens fora ilegal e questiona mesmo se houve realmente um leilão:

(...) opinor enim essein legequam ad diem proscriptiones venditionesquefiant, nimirum $\mathrm{K}$ alendas I unias. Aliquot post mensis et homo occisus est et bona venisse dicuntur. Profecto aut haec bona in tabulas publicas nulla redierunt nosque ab isto nebulone faceius eludimur quam putamus, aut, si redier unt, tabulaepublicaecor ruptaealique ratione sunt; nam lege quidem bona venire non potuisse constat (§ 128)

Agora creio que a última data na qual as proscrições e vendas podiam ocorrer foi fixada na lei - nomeadamente, o primeiro de junho. Alguns meses mais 
R etórica eAção P olítica: A Complexio no P ro R oscio Amerino de M arco T úlio Cícero

tarde, [R óscio] foi morto e disseram que sua propriedade foi vendida. D e todo modo, ou esta venda não foi declarada nos registros públicos, e fomos trapaceados por este patife mais seriamente do que pensamos, ou, se foi, os registros foram alterados de algum modo, pois é evidente que a propriedade não podia ser vendida em virtude da lei.

Cícero, com a ajuda dos amigos de R óscio, bons silanianos que eram, podia facilmente descobrir se havia um registro público do leilão das propriedades al egadas. A ausência de tal registro era um trunfo para o orador e, se 0 registro existia, poderia declará-lo uma fraude. E ntão, por que construir uma complexio aqui? N uma leitura atenta do discurso, percebemos que esta complexio significa uma pausa em seu ataque a $\mathrm{C}$ risógono. $\mathrm{O}$ orador imediatamente explica que está, naquele momento, falando por si mesmo, e não pelo jovem Róscio. D eclara que Róscio não tinha interesse em questionar qualquer alteração de propriedade (o que, mesmo remotamente, podia fazer com que jurados se sentissem ameaçados). Tudo o que desejava era a absolvição. M as C ícero, declarando que fala agora não como advogado, mas como um cidadão romano, questiona o comportamento "abominável" de C risógono (§§ 128-129). Porém como introduzir esta virada no discurso? E le não podia simplesmente distinguir seu próprio ponto de vista do de Róscio, no início do tratamento do tópico contra C risógono, sem perder uma vantagem real. U ma parte da complexio que endereçou a si mesmo, no início deste tópico, começa com a demanda de que Cícero se encontra na posição de defensor (§ 124). Separar seus interesses dos de seu cliente neste contexto confundiria sua tentativa de tranqüilizar o júri: ele e Róscio deviam concordar em não atacar a legitimidade das propriedades adquiridas pelos jurados durante as proscrições. M as Cícero precisava, depois, introduzir uma separação entre os seus sentimentos e os de seu cliente. E stritamente falando, devia interromper sua linha de argumentação de modo a fazer um novo ajuste. Como conduzir esta interrupção necessária? Com uma complexio. Com esta forma de argumentação, ele dá ao seu ataque uma nota extremamente vigorosa. E ntão, retoma o seu ataque com a saraivada de questões do $\S 130$, agora fal ando por si, e não por seu cliente.

Com isto, vemos que Cícero, no início de sua carreira, capitaliza o aspecto presentacional da complexio, como um símbolo de um argumento irrefutável. As formas da complexio no raciocínio diaerético das seções §§ 74-79 criam uma impressão de argumento forte, que ajuda a dissimular a fraqueza 
das conclusões, baseadas na caracterização dos envolvidos no caso. A asserção perfeitamente plausível de que 0 acusado podia ter contratado al guém para cometer 0 assassinato é refutada apenas pela al egação de sua inexperiênciae rusticidade. M as esta alegação é apresentada numa estrutura tal que Ihe garante a aparência de rigor, e o argumento fraco ganha uma aura de irrefutabilidade pelo modo como é apresentado. E ste efeito é um resultado direto do estilo, do aspecto presentacional da forma de argumentação usada por Cícero.

$D$ o mesmo modo, sua asserção de que $M$ agno era mais provavelmente o assassino, e não Róscio, é totalmente baseada no delineamento de seu caráter moral, aparentemente rigoroso pelo uso da complexio (§ 93). E sta aparência de rigor, validando o argumento com base em suposições de caráter, também reforça a validade das suposições.

O outro uso, no discurso, do aspecto presentacional da complexio é um tipo de pontuação no ritmo do argumento. A complexio é um modo de enfatizar o discurso, e o orador pode usá-la como uma espécie de pausa para auxiliar a memória, durante um argumento que, depois, resumirá (§ 128).

Torna-se claro, também, que Cícero redireciona a complexio de uma forma que não discutiu em seu texto retórico da juventude. E stas formas são estruturas de complexio, mas não compl exio verdadeira, de acordo com os exemplos do D el nventione, ou com a definição de Quintiliano; tanto em sua estrutura como em sua finalidade, divergem dos padrões retóricos. Temos, então, de ser cautelosos quando falamos de seu valor estilístico ou presentacional. Os três exemplos de estrutura de complexio neste discurso são características notáveis da criatividade de Cícero em expandir o uso dos mecanismos básicos da complexio. Alterando a referência temporal do presente para o passado, ele molda uma forma de argumentação que tem todo o impacto de uma complexio verdadeira, e não deixa ao adversário a possibilidade de responder (§ 120); alterando a finalidade da forma da complexio, Cícero converte um argumento fraco num ataque forte com finalidades extra-racionais. E ntão, ele pode apresentar seu próprio cliente numa complexio e provocar a piedade em relação ao acusado, ao mesmo tempo que declara sua inocência (§ 30). D e um modo ainda mais interessante, o orador confessa que ele mesmo está numa complexio (§ 124). E nquanto esta é uma tática para obter a indulgência, já tratada por oradores áticos, seu uso é especial mente penetrante. Cícero explicitamente declara os sentimentos conflitantes de sua audiência. Pode, então, anunciar um meio de resolver o conflito e, com isto, obter a licença para falar de um modo que não incite a hostilidade do júri. 
$N$ ão é em vão que podemos resumir a relação entre os argumentos éticos e o uso da complexio por Cícero. Já dissemos que os seus argumentos, usando complexio verdadeiras são construídos sobre - e, então, val idados extra-racional mente - suposições a respeito do caráter do acusado e do de seus oponentes. E stas suposições, que são éticas, pertencem aos argumentos ligados diretamente à questão principal: Róscio matou seu pai ou não? Todas as caracterizações do acusado são parte dos argumenta ex persona, que Cícero e sua audiência esperariam numa questão de fato ${ }^{12}$. Por extensão, as caracterizações, que levam ao argumento de que seria mais provável que outra pessoa tivesse cometido o crime, são exercícios semelhantes destes argumenta ex persona. 0 papel da complexio é, pois, tanto o de construir quanto, e retroativamente, o de val idar as suposições éticas nos argumentos rel evantes à questão. Por outro lado, a descrição de Cícero da complexio que atinge seu cliente simplesmente ajuda a estabelecer sua caracterização das partes envolvidas no caso. F inalmente, sua declaração de que el e próprio enfrenta uma complexio, de modo a falar sem ofender a audiência, toca a questão principal apenas indiretamente, mas funciona perfeitamente na arena jurídica romana, envolvendo orador e audiência, sendo um exemplo da complexio a serviço da retórica jurídica.

Vemos, no primeiro discurso criminal de Cícero, sua própria apreciação do val or da complexio, tanto como um veículo como um símbolo do argumento forte. 0 jovem orador compreende bem a inter-relação dos aspectos mecânicos e presentacionais desta forma de argumento. E le também sabe das possibilidades de variação na forma, tanto na construção dos argumentos, especialmente dos éticos, quanto do desenvolvimento dos apelos éticos úteis ao caso.

Consideramos a acusação muito mal calculada. A despeito da contradição fundamental da acusação de que R óscio era 0 assassino, por homens que estavam de posse das propriedades da vítima, sob a alegação de que ela estava entre os proscritos, os R oscii e C risógono pareciam que esperavam triunfar pela intimidação. U ma interpretação radicalmente diferente seria argumentar que os acusadores queriam a absolvição de R óscio. Pressionados pela presença de C risógono, que intimidava os patroni, R óscio seria deixado sem defesa, e teria de responder por si mesmo à acusação de assassinato. L ogica-

${ }^{12}$ Inv. 1. 34-36; 2.28-37. 
mente, suaúnica defesa possível seria dizer que seu pai estava entre os proscritos, logo, que não fora assassinado. Caso isto ocorresse, a acusação sairia ganhando, pois confirmaria os alegados direitos de propriedade de C risógono. Além disto, seria uma evasão legal da acusação de parricídio. Sua reputação estaria arruinada e nenhuma reivindicação futura sobre as propriedades seria apoiada por quem quer que seja.

A profundando esta idéia, poderíamos argumentar que a lei previa que pessoas podiam ser mortas com impunidade, se estivessem nas listas de proscritos ou se fossem mortas nos campos de batal ha da guerra civil. Cícero nos diz (§ 127) que a vítima era vista simplesmente como tendo sido morta no campo do adversário. E sta informação, não mencionada pela acusação, era acessível à defesa. Assim, 0 orador não precisaria fazer a juridicamente correta, mas problemática declaração de que seu cliente matara legalmente seu pai. Seu cliente seria absolvido, e o veredicto mostraria que o velho Róscio tinha sido proscrito, justificando legalmente a posse das propriedades por Crisógono.

Cremos, porém, que não podemos comprovar esta idéia. É certo que qualquer precedente legal que se apoiasse na tese de que a vítima fora proscrita seria complementado pela tese de que o acusado, mesmo que legalmente inocente, era aparentemente culpado do ultraje moral de parricídio. Seria esta ignomínia, assim como a admissão de que seu pai fora proscrito, que invalidariam qual quer apoio para suas reivindicações de restauração de propriedade. T. E. Kinsey objeta que uma absolvição, obtida com base em argumentos de que a vítima fora morta no campo adversário, não viciaria necessariamente uma futura petição do jovem Róscio para recuperar sua herança ${ }^{13}$. U ma vez absolvido, R óscio poderia repudiar a linha de raciocínio de Cícero, que o levara à absolvição. Além disto, o júri poderia ter absolvido o acusado sob outras bases. D aí, o próprio Cícero poder ter quebrado seu raciocínio para, de certo modo, contemporizar com o povo de Améria e com os nobiles romanos, que não tinham qualquer motivo para não apoiar as reivindicações de $R$ óscio quanto às suas propriedades. K insey argumenta também que as proscrições, incluindo os nomes, os assassinatos e os leilões de propriedades, pararam legalmente em 1 - de junho de 81 . Assim, mesmo que Cícero desejasse dar aos acusadores esta confissão, que eles queriam para a absolvição, não

${ }^{13}$ T. E. KIN SE Y, “A problem in Pro Roscio Amerino”, E ranos 79 (1981): 150-53. 
poderia arriscar-se desta forma. E rúcio teria simplesmente de mencionar a data do crime, após 1ㅇde junho de 81, para demolir a tese da defesa.

E ste argumento de Kinsey é baseado em sua interpretação de duas passagens do discurso ( $\S \S 21,128)$. É verossímil que o fim das proscrições em 1 o de junho de 81 signifique apenas o fim das inclusões de nomes nas listas de proscritos, e não uma garantia de anistia àqueles que foram proscritos anteriormente. A expressão proscriptiones venditionesque ( $\S 128)$ pode ser interpretada como o encerramento geral de todas as ações que envolviam as proscrições em 10 de junho de 81, mas não é impossível, na falta de outras fontes de informação, que o assassinato de proscritos, após esta data, e o leilão de suas propriedades continuassem permitidos pela lei.

Cícero, enfim, obteve a absolvição de seu cliente e a restauração de suas propriedades e, com o P ro R oscio A merino em mente, seu primeiro grande caso num tribunal, podemos passar ao exame de discursos da sua maturidade, onde o orador sistematicamente utiliza as propriedades persuasivas desta forma de argumentação, dando prosseguimento à pesquisa. 